\title{
Research of Injection Efficiency Function Based on Different Model- Driven Approach
}

\author{
Kaibin Wu \\ Nari Group Corporation (State Grid Electric Power Research Institute), Nanjing, 211000 China \\ Nari (Wuhan) Electrical Equipment \&Engineering Efficiency Evaluation Center, Wuhan, 430074, China
}

Corresponding author: Kaibin Wu

Cuiping $\mathrm{Xu}$

Hubei KeNeng Power Electronics Co., LTD, Wuhan 430074, China

Chaoyang $\mathrm{Xu} \&$ Jie Xiang

Nari Group Corporation (State Grid Electric Power Research Institute), Nanjing, 211000 China

Nari (Wuhan) Electrical Equipment \&Engineering Efficiency Evaluation Center, Wuhan, 430074, China

\begin{abstract}
Injection molding machine motor pump system energy consumption models were established for dosing pumps, servo motor pumps driven and other different ways, to get the comparative analysis of different ways driving injection molding machine energy consumption. The injection molding machine pump system was transformed under the case of better efficiency in the theoretical analysis, after transformation. Through empirical testing, obtaining and calculating system operating parameters of the injection molding machine, the actual benefit of the project was consistent with the theoretical value. It has a good reference value for the promotion of injection molding machine pump renovation projects.
\end{abstract}

KEYWORD: Injection molding machine; oil pump; energy consumption model; empirical test

\section{INTRODUCTION}

In the Research of the injection molding machine energy-saving technologies, Servo control, frequency control and energy research in the injection molding machine were forefront of the world especially in Japan and abroad as well as Europe and other countries (Root Peng Yun et al, 2011). Since there was a large overflow losses in conventional valvecontrolled injection molding machine, with the social development of injection molding technology requirements increased, domestic and foreign companies and research institutions had researched intensively (hi South crown et al, 2011).

YuzuruOhba etc. reaeared injection molding machines without pressure sensor senses torque observer, this system reduced noise and costs (Lin Kewei et al, 2011). By reducing the element and resonance phenomenon, Engr.Syed.Faiz.Ahmed of Nanyang Technological University had studied the implant system designed for injection molding machine, providing a new approach of the injection molding machine control applications in industrial automation. EJ.Swider etc. studied the preliminary control of the microcontroller-based. N.Akasakala of Japan studied the multi-AC servo motor drive in synchronous position control and pressure control methods of injection molding machine. Y.Inaba etc. studied the pressure control of all-electric injection molding machine servo mechanical (Zhang Tao et al, 2010). S.Nakamura studied the electric motor drive system and ball screw injection molding machine applicated at a high load. Proportional variable pump system of hydraulic injection molding machine was mainly studied in saving injection molding machine in domestic (Li Qinghong et al, 2011). The composite control research started late, and its level was relatively backward. Fluid Engineering Institute of Zhejiang University had made some achievements in the study of variable frequency pump control system;Long Quan of Taiyuan University of Technology had achieved some results in the electrohydraulic control of injection energy efficiency (Min, 2007). New Driving Technology Center of Southwest Jiaotong University has been committed to research in this area, and has achieved some results. South Yu rong etc. of Zhejiang University studied the Repetitive control in electric injection molding machine control position servo system, presenting AC servo system control method based on electric injection molding machine. Although the research of complex control technology, servo control technology and other aspects of induction heating modules of the injection molding machine were involved, but the relevant research is not deep enough. the study of the injection molding machine servo-driven hydraulic system and an electromagnetic induction heating system was not deep enough, and energysaving technologies integration of injection molding machine were less researched. It can't provide a comprehensive overall solution for energy-saving injection molding machine. 


\section{INJECTION MOLDING MACHINE ENERGY MODEL}

Injection molding process is currently one of the main production of plastic processing, due to the injection molding process can be made of a variety of complex shapes and precision injection molding products (Zhang Jialin, 2010), so products are widely used in industrial, consumer electronics and daily life. With the improvement of optical and precision manufacturing, such as optical lenses, precision gears and other precision injection molded parts, the conventional injection molding can't meet the requirements of growing concern on the precision injection, requiring precise closed-loop control of the injection molding process parameters (Zhang Friends of the root, 2008).

There are three kinds of injection molding machine drive system of hydraulic drive system, allelectric and electro-hydraulic hybrid currently. Allelectric injection molding machine is too costly, so its application is limited, the hydraulic injection molding machine is the current main market (Shen C $\mathrm{Y}$ et al, 2007). The traditional hydraulic injection molding machine is driven by a three-phase motor dosing pumps with power system of the hydraulic system, and the hydraulic pressure and flow control of the system were realized by proportional pressure valve and the proportional valve. In the entire injection molding process, the motor runs at rated power with excess flow back through the overflow tank serious waste of energy. In addition, as the proportional pressure valve and the proportional valve in response to the speed limit and pressure flow basic open-loop control, it is difficult to meet the requirements of precision injection molding (Zhou JA, 2007) (SYED JAVED A R, 2006) (QUAN Long et al, 2006). With the servo drive control technology, servo motor direct drive from a variety of electrohydraulic servo system began to appear, which overcomes the shortcomings of traditional valvecontrolled hydraulic system, using system pressure, flow, dual-loop control, in accordance with the actual needs of the flow and pressure oiling, overcoming the high energy consumption of the general quantitative pump system pressure overflew, it has advantages of wide speed range, high precision control, energy-saving effect and so on (J. Zhou et al, 2006).

Compared with dosing pumps, servo gear pump has the three following aspects of energy-saving effects.

The volumetric efficiency values of Common quantitative vane pump is $88-90 \%$, while the volumetric efficiency of the servo gear pump is $95 \%$, thus replacing the pump could achieve energy saving rate of about $5 \%$. (Volumetric efficiency: the ratio of the actual pump flow to the theory pump).

Ordinary three-phase asynchronous motor power factor is between $0.75-0.85$, and high-performance servo motor power factor can reach above 0.98 , so replacing efficient motors and improving the power factor can achieve energy savings rate of $13 \%-20 \%$. In the Injection molding process, the dosing pump motor operates at rated power, there is excess flow back to the tank through the overflow with serious waste of energy in the entire operation of the injection molding process. But the use of servo motor technology department in accordance with the actual flow and pressure needed to supply could implement energy-saving effect of about $30 \%$, corresponding to energy consumption model for the establishment of this major energy savings are as follows:

Injection molding process is generally divided into injection unit in, clamping, injection, packing, cooling, material storage, mold, thimble, nine stages injection unit back and other 9 stages, each step takes time, pressure, speed, position, etc. with.

The injection system maximum pressure $\mathrm{F}$, maximum flow rate $\mathrm{Q}$, the motor speed $\mathrm{n}$, time $\mathrm{T}$ and each operating pressure $F_{i}$, flow $Q_{i}$, speed $n_{i}$, time $t_{i}$, draw each injection molding machine operation and corresponding power consumption solid carrier, respectively as shown in equation (1), (2):

$$
\begin{gathered}
X_{i}=\frac{P F_{i} Q_{i} n_{i} t_{i}}{F Q n T} \\
K_{i}=\frac{t X_{i}}{t_{i}}
\end{gathered}
$$

Where, $\mathrm{i}=1,2 \ldots \ldots, \mathrm{m}$ defined as the nine stages of the process of injection molding machines.

Because the asynchronous motor runs with constant torque, the dosing pump operating speed of each action was:

$$
n_{i}=n
$$

According to the percentage of traffic when the servo motor speed changes, the servo motor pump speed of each operation was:

$$
n_{i}=n^{*} Q_{i} \%
$$

The operation of the injection molding process the required pressure, flow, time is substituted into the formula to calculate the injection molding machine each action dosing pumps and servo gear pump real load consumption $\mathrm{Xi}$, and the corresponding power $\mathrm{K}_{\mathrm{i}}$, after comparing a single product can be calculated the production cycle of quantitative pump and the servo gear pump power value as the theoretical formula (5), (6), and further calculates the energy saving effect.

$$
\begin{gathered}
X=\sum_{i=1}^{m} X_{i} \\
K=\sum_{i=1}^{m} K_{i}
\end{gathered}
$$


Where, $\mathrm{i}=1,2 \ldots \ldots, \mathrm{m}$ defined as the nine stages of the process of injection molding machines.

\section{INJECTION MOLDING MACHINE EFFICIENCY FUNCTION THEORETICAL AND EMPIRICAL TEST}

\subsection{Calculation energy savings based on the theoretical model}

Injection molding machine selection: a brand 280T injection molding machine.

1. Prototype Parameters: Motor Power: 22kw; electric power: $16 \mathrm{kw}$; motor speed: $975 \mathrm{r} / \mathrm{min}$;

2. Products parameters: product weight: $300 \mathrm{~g}$; molding surface area $42 \times 26=1092 \mathrm{~cm}^{2}$;

3. Molding cycle: $45 \mathrm{~s}$; Raw material: PP.

Pressure and flow of the movement of injection molding machine and other known conditions and two pump energy consumption calculated as shown in Table 1, Table 2:

Table 1 Energy consumption theoretical value of single work cycle dosing pump

\begin{tabular}{|c|c|c|c|c|c|}
\hline $\begin{array}{l}\text { Each action decom- } \\
\text { position }\end{array}$ & $\begin{array}{l}\text { Operation } \\
\text { time: } s\end{array}$ & $\begin{array}{l}\text { Operating pres- } \\
\text { sure: bar, } \\
\mathbf{F} \leq \mathbf{1 4 0}\end{array}$ & $\begin{array}{l}\text { The ratio of each opera- } \\
\text { tion flow to } Q \text { system } \\
\text { flow than } Q \leq 99 \%\end{array}$ & $\begin{array}{l}\text { Real load con- } \\
\text { sumption } X: k W h\end{array}$ & $\begin{array}{l}\text { Corresponding } \\
\text { power } K,: \mathbf{k W}\end{array}$ \\
\hline injection unit in & 2.5 & 85 & 60 & $\mathrm{X} 1=0.0056$ & $\mathrm{~K} 1=8.1$ \\
\hline injection & 5 & 125 & 90 & $\mathrm{X} 3=0.0248$ & $\mathrm{~K} 3=17.9$ \\
\hline packing & 30 & 70 & 30 & $X 4=0.0167$ & $\mathrm{~K} 4=3.3$ \\
\hline cooling & 14 & & & $X 5=0.0150$ & $\mathrm{~K} 5=3.86$ \\
\hline thimble & 3 & 35 & 35 & $X 8=0.0016$ & $\mathrm{~K} 8=1.9$ \\
\hline injection unit back & 2 & 75 & 60 & $X 9=0.0039$ & $\mathrm{~K} 9=7.0$ \\
\hline $\begin{array}{l}\text { The average statistics } \\
\text { throughout the cycle }\end{array}$ & 45 & & & $X=0.155$ & $\mathrm{~K}=12.4$ \\
\hline
\end{tabular}

Table 2 Energy consumption theoretical value of single work cycle servo pump

\begin{tabular}{|c|c|c|c|c|c|c|}
\hline $\begin{array}{l}\text { Each action decom- } \\
\text { position }\end{array}$ & $\begin{array}{l}\text { Operation } \\
\text { time: } s\end{array}$ & $\begin{array}{l}\text { Operating } \\
\text { pressure: bar, } \\
\text { F } \leq 140\end{array}$ & $\begin{array}{l}\text { The ratio of each opera- } \\
\text { tion flow to } Q \text { system } \\
\text { flow than } Q \leq 99 \%\end{array}$ & $\begin{array}{l}\text { Motor } \\
\text { speed }\end{array}$ & $\begin{array}{l}\text { Real load } \\
\text { consumption } \\
\mathrm{X}: \mathrm{kWh}\end{array}$ & $\begin{array}{l}\text { Corresponding } \\
\text { power } K,: \text { kW }\end{array}$ \\
\hline injection unit in & 2.5 & 85 & 60 & 1080 & $\mathrm{Y} 1=0.0033$ & $\mathrm{H} 1=4.75$ \\
\hline injection & 5 & 125 & 90 & 1620 & $\mathrm{Y} 3=0.0220$ & $\mathrm{H} 3=15.84$ \\
\hline packing & 30 & 70 & 30 & 540 & $\mathrm{Y} 4=0.0050$ & $\mathrm{H} 4=0.6$ \\
\hline cooling & 14 & & & & $Y 5=0$ & $\mathrm{H} 5=0$ \\
\hline thimble & 3 & 35 & 35 & 630 & $Y 8=0.0013$ & $\mathrm{H} 8=1.56$ \\
\hline injection unit back & 2 & 75 & 60 & 1080 & $Y 9=0.0005$ & $\mathrm{H} 9=0.9$ \\
\hline $\begin{array}{l}\text { The average statistics } \\
\text { throughout the cycle }\end{array}$ & $45 \mathrm{~s}$ & & & & $\mathrm{Y}=0.111$ & $\mathrm{H}=8.8$ \\
\hline
\end{tabular}

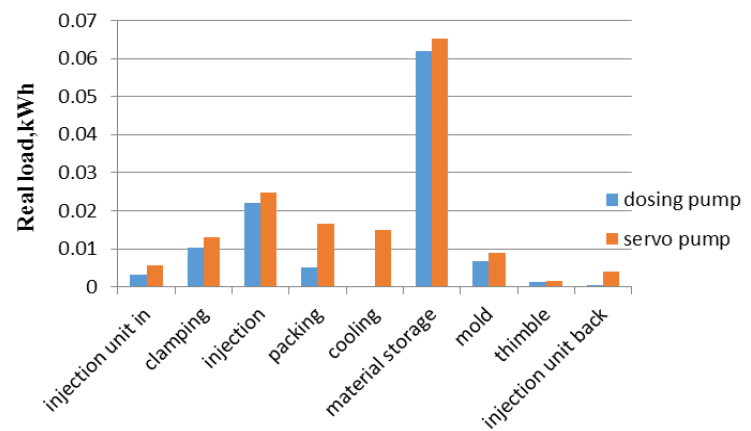

Chart 1 Comparison chart of real time energy consumption theoretical calculation value of dosing pump and servo pump

Comparison chart of real time energy consumption theoretical calculation value of dosing pump and servo pump was shown in chart 1.
Based on the above theoretical value, this model shows that the energy saving effect of this product, the servo pump overflow by reducing the dosing pumps for the energy loss can be achieved(12.48.8)/12.4=29.03\%.

The increase of energy saving rate due to the increase of volumetric efficiency is $5 \%$, due to the increase of the power factor is $15 \%$. By changing the quantitative pump to servo gear pump, the overall effect should be about $49.03 \%$.

\subsection{Experimental verification after modification of injection molding machine}

The pump consumption data of the above 280T injection molding machine were collected before and after the servo motor transformation during the production of the same product, Collection time is 2 
hours, collecting consumption data were shown in Table 3.

Table 3 The servo motor measured data before and after the transformation

\begin{tabular}{|l|l|l|l|l|l|}
\hline & \multicolumn{2}{|l|}{ dosing pump } & \multirow{2}{*}{ servo pump } \\
\cline { 2 - 3 } \cline { 5 - 5 } Time & $\begin{array}{l}\text { electric } \\
\text { meter } \\
\text { readings } \\
(\mathrm{kWh})\end{array}$ & $\begin{array}{l}\text { electric } \\
\text { meter } \\
\text { readings } \\
(\mathrm{kWh})\end{array}$ & modulus \\
\hline $8: 00$ & 11 & 0 & $13: 00$ & 72.6 & 0 \\
\hline $9: 00$ & 22.6 & 78 & $14: 00$ & 78.6 & 78 \\
\hline $10: 00$ & 34.3 & 157 & $15: 00$ & 84.5 & 157 \\
\hline
\end{tabular}

Through the above actually measured power consumption can be drawn: General Motors average one hour consumes $11.65 \mathrm{kWh}$, servo motor consumes an average of one hour $5.95 \mathrm{kWh}$, calculate the average energy-saving rate $\mathrm{w}=50.2 \%$, and $49.03 \%$ compared to the theoretical value, error rate is only $2.33 \%$ in good agreement.

\section{CONCLUSION}

(1) Injection molding machine motor pump system energy consumption models were established for dosing pumps, servo motor pumps driven and other different ways, to get the comparative analysis of different ways driving injection molding machine energy consumption;

(2) Based on the Injection molding machine energy model, the transformation project is expected to get the case of energy efficiency by theoretical analysis;

(3)Through empirical testing, obtaining and calculating system operating parameters of the injection molding machine, the actual benefit of the project was consistent with the theoretical value. It has a good reference value for the promotion of injection molding machine pump renovation projects.

\section{REFERENCES}

hi South crown, root Yun Peng, Yan Guoyi, et al. General Electric Proportional control hydraulic pump open loop experimental study [J]. Hydraulic and Transmission, 2011 (7): 65-67.

J.Zhou; L.-S.Turng; A.Kram schuster Single and Multi Objective Optimization for Injection Molding Using Numerical Simulation with Surrogate Models and Genetic Algorithms 2006(5)

Lin Kewei, Xu Kaijie, weeks to root. Situation saving technology injection molding machine hydraulic system analysis [J]. Engineering plastics applications, 201, 39 (8): 84-87.

Li Qinghong, Wu Long. Design of PLC control system based on the hydraulic injection molding machine $[\mathrm{J}]$. Nantong University: Natural Science Edition, 2011, 10 (4): 22-25.

Min. Trend of energy-saving injection molding machine [J]. Plastic additives, 2007 (4): 54-55.
QUAN Long; LIU Shiping Improve the Kinetic performance of the pump controlled clamping unit in plastic injection molding machine with adaptive control strategy-Chinese Journal of Mechanical Engineering 2006(01)

Root Peng Yun, Yuan silver M, Tao Jianfeng, and so on. Joint press control valve pump master cylinder system modeling and simulation [J]. Machine Tool \& Hydraulics, 2011, 39 (13): 100-102.

Shen C Y;Wang L X;Li Q Optimization of injection molding process parameters using combination of artificial neural network and genetic algorithm method 2007(2/3)

SYED JAVED A R Analysis of energy loss during plasticization in an hydro mechanical injection molding machine 2006(04)

Zhang Friends of the root. Research Analysis saving injection molding machine hydraulic drive system [J]. Hydraulic and pneumatic seals, 2008, 28 (3): 1-5.

Zhang Jialin. Saving injection molding machine hydraulic system of regulation based on energy research [D]. Hangzhou: Department of Mechanical Engineering, Zhejiang University. 2010.

Zhang Tao, Libin Li, Li Ziyu. Study saving injection molding machine hydraulic servo drive technology [J]. Electrical Engineering Technology, 2010, 39 (8): 74-75.

Zhou JA; Turng LS Process optimization of injection molding using an adaptive surrogate model with Gaussian process approach 2007(5) 